Check for updates

Cite this: RSC Adv., 2019, 9, 7975

Received 30th November 2018 Accepted 7th February 2019

DOI: $10.1039 / c 8 r a 09840 a$

rsc.li/rsc-advances

\section{A comparative study of side-chain-type poly(ether ether ketone) anion exchange membrane functionalized with different hetero-cycloaliphatic quaternary ammonium groups $\dagger$}

\author{
Dan Yao, ${ }^{a}$ Tonghui Wei, ${ }^{b}$ Lichao Shang, ${ }^{a} \mathrm{Hui} \mathrm{Na}^{\mathrm{a}}$ and Chengji Zhao (DD *a
}

\begin{abstract}
Anion exchange membranes based on side-chain-type quarternized poly(ether ether ketone)s (QPEEKs), containing different hetero-cycloaliphatic quaternary ammonium groups, were prepared via a multi-step procedure, including polycondensation with a monomer containing pendant methylphenyl groups, bromomethylation, and followed by quaternization with 1-methylpyrrolidine (MPY), 1-methylpiperidine (MPRD), 1-methylimidazole (MIDZ) and $N$-methyl morpholine (MMPH), respectively. The properties of these membranes were then compared with the properties of conventional quarternized poly(ether ether ketone) s containing benzyltrimethylammonium (QPEEK-TMA). Model compounds, QMPY, QMPRD, QMIDZ and $\mathrm{QMMPH}$, were synthesized and used to quantitatively compare the alkaline stability of hetero-cycloaliphatic quaternary ammonium groups using ${ }^{1} \mathrm{H}$ NMR. The results of this study indicated that the alkaline stability of all these model compounds is in the order of QMPY > QMPRD > QTMA > QMIDZ > QMMPH. These QPEEKs membranes display superior thermal, dimensional and mechanical stability. QPEEK-TMA, QPEEKMPY and QPEEK-MPRD exhibit higher hydroxide conductivities and lower activation energies than QPEEKMIDZ and QPEEK-MMPH. Furthermore, after exposure to $1 \mathrm{M} \mathrm{NaOH}$ at $60{ }^{\circ} \mathrm{C}$ for 24 days, QPEEK-MPY and QPEEK-MPRD demonstrated a loss in hydroxide conductivity of $28.5 \%$ and $33.4 \%$, respectively. Both values were lower than that of QPEEK-TMA (37.7\%). Therefore, among these side-chain-type QPEEKs membranes, QPEEK-MPY and QPEEK-MPRD, containing benzylmethylpyrrolidinium and benzylmethylpiperidinium as cation head-groups, are promising AEM materials for fuel cell construction.
\end{abstract}

\section{Introduction}

The current pattern of mankind's energy consumption is facing more and more problems and challenges, including the excessive dependence on traditional fossil fuels, such as coal and oil. Also, it causes environmental pollution and greenhouse gas emission due to combustion of fossil fuels. ${ }^{1}$ Therefore, the development of clean and sustainable energy sources for replacing fossil fuels has been initiated. At present, there are many possible alternative energy sources to the combustion of fossil fuels under investigation, for example, solar energy, wind energy, hydrogen energy, nuclear energy, tidal energy and bioenergy. However, utilization of new energy requires energy generation, storage and release. ${ }^{2,3}$

\footnotetext{
${ }^{a}$ Alan G. MacDiarmid Institute, College of Chemistry, Jilin University, Changchun 130012, P. R. China. E-mail: zhaochengji@jlu.edu.cn; Fax: +86-0431-85168870; Tel: +86-0431-85168870

${ }^{b}$ School of Mechanical and Aerospace Engineering, Jilin University, Changchun 130025, P. R. China

$\dagger$ Electronic supplementary information (ESI) available. See DOI: 10.1039/c8ra09840a
}

In the past decades, hydrogen fuel cells have become the new and promising energy technology due to their high energy conversion efficiency, superior portability and environmental friendliness. ${ }^{4,5}$ As one type of fuel cells, anion exchange membrane fuel cells (AEMFCs) have drawn tremendous attention due to their potential advantages over common proton exchange membrane fuel cells (PEMFCs), including enhanced oxygen reduction kinetics and faster fuel oxidation kinetics under alkaline conditions. This technology would allow using low-cost, non-precious metal catalysts and reducing the overall cost of AEMFCs greatly. ${ }^{6-10}$ As the core component in AEMFCs, anion exchange membrane (AEM) serves as the electrolyte for hydroxide ion transport between electrodes and separates the fuel from the oxidant. ${ }^{11}$ Hence, in order to ensure efficient and stable operation of AEMFCs, the ideal AEM must possess high enough hydroxide conductivity (the conductivity must meet the requirement: $>10 \mathrm{mS} \mathrm{cm}^{-1}$ at room temperature and close to $100 \mathrm{mS} \mathrm{cm}^{-1}$ as far as possible at working temperature), satisfactory thermal and chemical stability, and sufficient film forming ability, mechanical strength and dimensional stability. ${ }^{12}$ 
Quaternary ammonium (QA) functionalized polymer electrolyte membranes, especially those using trimethylamine (TMA) as the quaternary reagent, have been widely investigated as potential AEM materials. Most of them were prepared by tethering QA groups to the backbone of chloromethylated or bromomethylated aromatic polymers by immersing them in TMA solution. ${ }^{13,14}$ However, conventional QA-functionalized AEMs exhibit very low ionic conductivity and poor alkaline stability at high $\mathrm{pH}$ and high temperature conditions. Therefore, many researchers have concentrated on molecular design to improve the performance of AEMs. Some achievements have been made in this field by finding alternatives to QA functional groups. Marino et al. studied the alkaline stability of different cationic model compounds in high-pH solutions by determining the half-times of the compounds using NMR analysis. The results suggested that aliphatic-heterocyclic QA headgroups exhibited excellent alkaline stability compared to that of the conventional benzyltrimethylammonium head-groups, especially under extreme accelerated experiment conditions. ${ }^{15}$ For example, piperidinium demonstrated high resistance to both nucleophilic substitution and elimination in $6 \mathrm{M} \mathrm{NaOH}$ at elevated temperatures. Recently, many researchers also reported that AEMs, based on polymers containing $N$-alkylpyrrolidinium and benzyl- $N$-methylmorpholinium head-groups, exhibited higher alkaline stability than the commercial Tokuyama A201 AEMs. ${ }^{16-18}$ Ponce-gonzález et al. reported that radiation-grafted AEMs, containing saturated-heterocyclic head-groups, displayed a relatively good alkaline stability, conductivity and in situ fuel cell performance. ${ }^{19}$ They believe that the benzyl- $N$-methylpyrrolidinium head-group is the most promising alternative to benzyltrimethylammonium headgroup.

As recently reported, locating the sulfonic acid groups on the side chains of the polymer backbones could improve the mobility of ions, thus, promoting phase separation and increasing proton conductivity. Nowadays, in some studies of AEMs, a similar method has been utilized to tether cationic head-groups to the side chain of the polymer for improving the hydroxide conductivity of AEMs without sacrificing their favourable mechanical properties. ${ }^{20,21}$

Aromatic polymers, such as poly(ether ether ketone)s (PEEK), are the most extensively used starting materials for the preparation of AEMs by grafting QA groups onto the main polymer backbone. ${ }^{22-24}$ However, it was reported that the backbone undergoes cleavage of $\mathrm{C}-\mathrm{O}$ bonds under the attack of hydroxide anions when electron-withdrawing cationic headgroups are in close proximity. ${ }^{25}$ It was postulated that attaching cationic head-groups to the backbone via a bulky spacer in the side chain could isolate the electron-withdrawing effect of the cation from the aromatic $\mathrm{C}-\mathrm{O}$ bonds, thereby, enhancing the alkaline stability of AEMs.

In this study, we synthesized a series of PEEKs with pendant methylphenyl groups, which gave us a chance to prepare sidechain-type AEMs bearing cationic head-groups, linked to backbones via bulky spacers in the side chains. After bromomethylation of methylphenyl-containing PEEKs, AEMs, based on aliphatic-heterocyclic QA head-groups, were prepared via
Menshutkin reaction using 1-methylpyrrolidine (MPY), 1-methylpiperidine (MPRD), 1-methylimidazole (MIDZ) and $N$-methyl morpholine (MMPH) as quaternary reagents, respectively. Quarternized poly(ether ether ketone)s (QPEEKs) containing benzyltrimethylammonium head-groups were also prepared using trimethylamine (TMA) for comparison. The purpose of this study was mainly to compare the characteristics of AEMs containing different aliphatic-heterocyclic QA groups, including ionic exchange capacity (IEC), thermal stability, dimensional stability, mechanical properties, ionic conductivity, especially the effect of hydroxide conductivity on alkaline stability, mechanical properties and ${ }^{1} \mathrm{H}$ NMR spectra after aging in alkaline solution. In addition, a series of model compounds with aliphaticheterocyclic QA cations were synthesized and used to characterize degradation of these cations using ${ }^{1} \mathrm{H}$ NMR spectroscopy. It would help to clarify the alkaline stability of QPEEKs with relevant cationic groups on side chain when exposed to alkaline solutions. In this paper, the AEMs with side-chain-type configuration and different aliphatic-heterocyclic QA head-groups are discussed in detail, comparing related properties, especially ionic conductivity and alkaline stability.

\section{Experimental section}

\section{Materials}

4,4-Difluorobenzophenone (DFBP) was purchased from Yanbian Longjing chemical company. $N$-Bromosuccinimide (NBS, 99\%), benzoyl peroxide (BPO, 99\%), MPY (98\%), MPRD (97\%), MIDZ (99\%), MMPH (99\%), $p$-benzoquinone (99\%) and $p$-toluidine (AR, 99\%) were obtained from Aladdin Reagent Co. Ltd. Trimethylamine in methanol (TMA, $3.2 \mathrm{~mol} \mathrm{~L}^{-1}$ ) was purchased from TCI. All other reagents and solvents were purchased from Tianjin Tiantai chemical company and used without further purification.

\section{Synthesis of model compounds}

The synthesis of benzyltrimethylammonium model compound (QTMA) was described by us earlier. ${ }^{26}$ One $\mathrm{mL}(8.69 \mathrm{mmol})$ benzyl chloride was dissolved in $40 \mathrm{~mL}$ ethyl alcohol in a $100 \mathrm{~mL}$ three-neck round bottom flask, equipped with a mechanical stirrer and a condenser, and then $5.43 \mathrm{~mL}(17.38$ mmol) TMA was added to the flask. The reaction mixture was stirred at $78{ }^{\circ} \mathrm{C}$ for $6 \mathrm{~h}$. Finally, the mixture was washed with diethyl ether and filtered. The product was washed with diethyl ether eight times and dried in a vacuum oven at $80^{\circ} \mathrm{C}$ for $48 \mathrm{~h}$.

As shown in Scheme 1, benzylmethylpyrrolidine, benzylmethylpiperidine, benzylmethylimidazole and

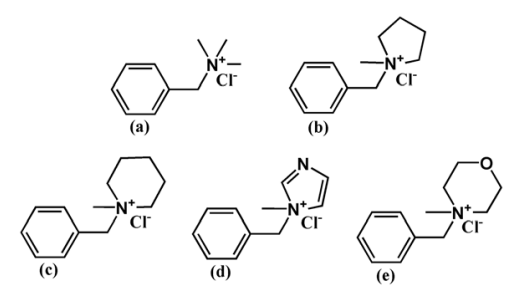

Scheme 1 Chemical structures of model compounds: QTMA (a), QMPY (b), QMPRD (c), QMIDZ (d) and QMMPH (e). 
benzylmethylmorpholine model compounds were synthesized using the similar procedure, employing MPY, MPRD, MIDZ and MMPH as the quaternary reagents. These model compounds with aliphatic-heterocyclic QA are denoted as QMPY, QMPRD, QMIDZ and QMMPH, respectively. Taking QMPY as an example, the synthesis was carried out as follows. One $\mathrm{mL}$ (8.69 $\mathrm{mmol}$ ) benzyl chloride was dissolved in $40 \mathrm{~mL}$ ethyl alcohol in a $100 \mathrm{~mL}$ three-neck round bottom flask equipped with a mechanical stirrer and a condenser, and then $1.85 \mathrm{~mL}(17.38$ mmol) MPY was added into the flask. The reaction mixture was stirred at $78^{\circ} \mathrm{C}$ for $6 \mathrm{~h}$. Finally, the product was precipitated in diethyl ether, filtered off, washed with diethyl ether eight times and dried in a vacuum oven at $80^{\circ} \mathrm{C}$ for $48 \mathrm{~h}$.

\section{Synthesis of bromomethylated poly(ether ether ketone)}

The 4-methylphenyl hydroquinone (He-MQ) monomer was synthesized according to procedure, used in our previous study. ${ }^{27}$ Poly(ether ether ketone) containing methylphenyl groups was synthesized as follows. He-MQ (8.00 g, $40.00 \mathrm{mmol})$, DFBP (8.72 g, $40.00 \mathrm{mmol})$, anhydrous potassium carbonate $(5.52 \mathrm{~g}, 40.00$ mmol), dimethyl sulfoxide (DMSO, $40 \mathrm{~mL}$ ) and toluene $(18 \mathrm{~mL}$ ) were added to a $250 \mathrm{~mL}$ three-neck round bottom flask equipped with a mechanical stirrer, a nitrogen inlet and a condenser. Toluene was added and the reaction mixture was heated to $140{ }^{\circ} \mathrm{C}$, refluxed for $4 \mathrm{~h}$ and then heated to $180^{\circ} \mathrm{C}$ to remove toluene. The product was precipitated in cold distilled water when the mixture became very viscous after $5 \mathrm{~h}$. Finally, the product was filtered off, smashed, washed with boiling deionized water more than ten times and dried under vacuum at $80{ }^{\circ} \mathrm{C}$ for $48 \mathrm{~h}$.

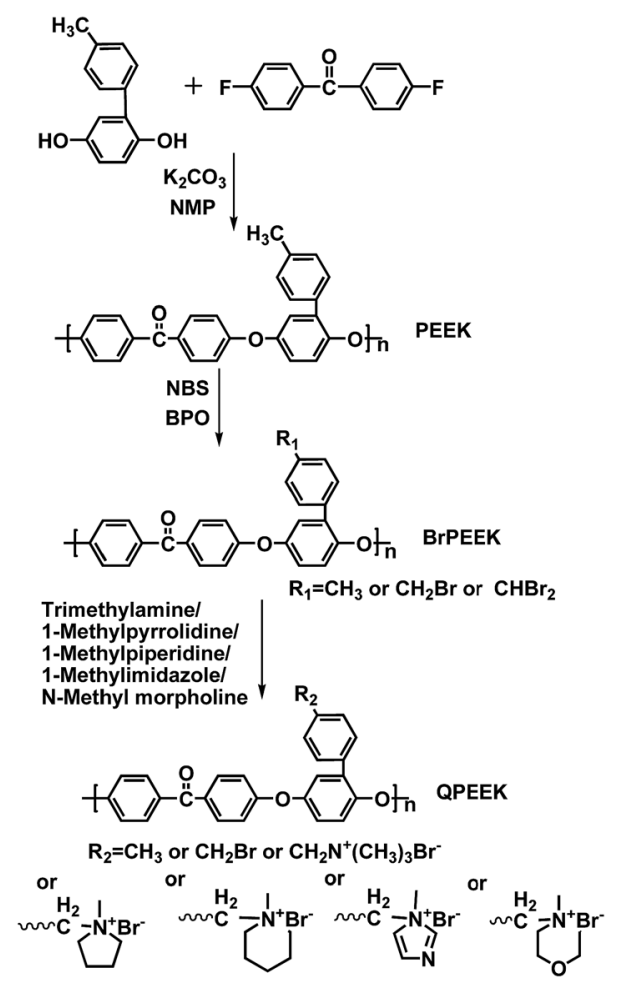

Scheme 2 Synthesis of PEEK, BrPEEK-X and QPEEK.
The synthesis of bromomethylated PEEK is shown in Scheme 2. Bromomethylation of PEEK, a free-radical substitution reaction, is mild and controllable, which distinguishes it from the usual chloromethylation reaction. NBS and BPO were used as the brominating reagent and the initiator, respectively. The product was denoted as BrPEEK-X, where $\mathrm{X}$ is the ratio of NBS to PEEK. Taking BrPEEK-1.2 as an example, the detailed procedure is as follows. The powder of PEEK ( $3.00 \mathrm{~g}, 7.94 \mathrm{mmol}$ ) was dissolved in dry 1,1,2,2-tetrachloroethane in a $100 \mathrm{~mL}$ three-neck round bottom flask, equipped with a mechanical stirrer, a nitrogen inlet and a condenser. When the color of the mixture became orange, NBS $(1.70 \mathrm{~g}, 9.52 \mathrm{mmol})$ and BPO (0.23 g, 0.95 $\mathrm{mmol}$ ) were added into the flask. The mixture was heated to $180^{\circ} \mathrm{C}$ for $10 \mathrm{~h}$ and turned claret-red gradually. Finally, the lightyellow polymer was precipitated in ethanol, washed with ethanol ten times and dried in a vacuum oven at $70^{\circ} \mathrm{C}$ for $10 \mathrm{~h}$.

\section{Synthesis of QPEEKs using TMA, MPY, MPRD, MIDZ, and MMPH}

The powder of BrPEEK-1.2 $(3.00 \mathrm{~g}, 5.01 \mathrm{mmol})$ was dissolved in $\mathrm{N}$ methyl-2-pyrrolidone (NMP) in a $100 \mathrm{~mL}$ three-neck round bottom flask equipped with a mechanical stirrer and a condenser. Then MPY $(1.06 \mathrm{~mL}, 10.02 \mathrm{mmol})$ was added into the flask and the reaction was kept at $60{ }^{\circ} \mathrm{C}$ for $12 \mathrm{~h}$. Later the solution was cast onto a flat glass plate and thermally treated under vacuum at $60{ }^{\circ} \mathrm{C}$ for $48 \mathrm{~h}$ to get rid of the residual NMP solvent. Finally, the membrane was removed from the glass, cut into pieces, washed with acetone ten times and dried in a vacuum oven at $80^{\circ} \mathrm{C}$ for $48 \mathrm{~h}$. The obtained product was named QPEEKMPY. Using a similar procedure, QPEEK-TMA, QPEEK-MPRD, QPEEK-MIDZ and QPEEK-MMPH were also synthesized.

\section{Preparation of AEMs}

Membranes, based on these QPEEKs, were fabricated using the solution casting method as shown in Scheme 3. For example, QPEEK-MPY $(1.0 \mathrm{~g})$ was dissolved in $10 \mathrm{~mL}$ NMP, and then the mixture was cast onto a flat glass plate and thermally treated under vacuum at $60{ }^{\circ} \mathrm{C}$ for $48 \mathrm{~h}$ to remove the residual solvent. The membrane was removed from the glass plate, immersed in $1 \mathrm{M} \mathrm{NaOH}$ solution for $24 \mathrm{~h}$ at room temperature and washed with deionized water ten times to remove extra ions. Finally, the hydroxide $\left(\mathrm{OH}^{-}\right)$counterion form membranes were obtained. All membranes were kept in a nitrogen filled ziplock bag before testing to avoid access to $\mathrm{CO}_{2}$.

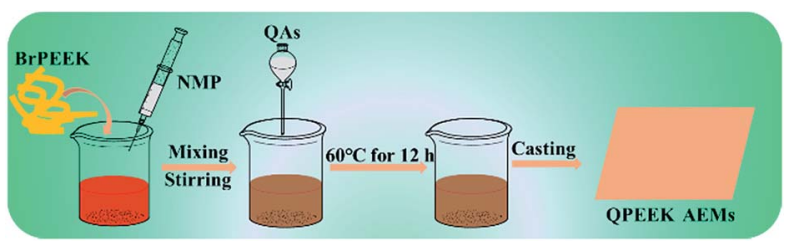

Scheme 3 Preparation of AEMs. 


\section{Characterization and measurement}

Chemical structures of the model compounds, the monomer, PEEK, BrPEEK-X and QPEEKs were analyzed using ${ }^{1} \mathrm{H}$ NMR spectroscopy (in $\mathrm{CDCl}_{3}$ and/or DMSO), performed on a Bruker 510 spectrometer $(500 \mathrm{MHz})$ with tetramethylsilane (TMS) as a reference. To determine the thermal properties of AEMs, thermogravimetric analysis (TGA) was performed on a Perkin Elmer Pyris 1 TGA instrument with a heating rate of $10{ }^{\circ} \mathrm{C} \mathrm{min}{ }^{-1}$ in the range of 100 to $800{ }^{\circ} \mathrm{C}$ under nitrogen atmosphere. A SHIMADZU AG-1 $1 \mathrm{KN}$ was used to explore the mechanical properties of QPEEK membranes at a speed of $2 \mathrm{~mm} \mathrm{~min}^{-1}$. At least ten samples $(15 \mathrm{~mm} \times 4 \mathrm{~mm})$ were tested, and the average values of mechanical properties were calculated and recorded. All measurements were taken on membranes in $\mathrm{OH}^{-}$form.

Alkaline stability test of model compounds. The alkaline stability of model compounds was determined using ${ }^{1} \mathrm{H}$ NMR after aging the model compounds in $1 \mathrm{M}$ sodium deuteroxide deuterium oxide solution $\left(\mathrm{NaOD} / \mathrm{D}_{2} \mathrm{O}\right)$ at $60{ }^{\circ} \mathrm{C}$ periodically.

Calculation of bromination. The average bromine content of each repeating unit of BrPEEK was determined accurately by ${ }^{1} \mathrm{H}$ NMR using the following formula:

$$
D_{\mathrm{Br}}=\frac{12 A_{\mathrm{H}_{9}}}{3 A_{\mathrm{H}_{9}}+2 A_{\mathrm{H}_{8}}},
$$

where $D_{\mathrm{Br}}$ represents the number of bromomethyl functional groups in each repeating unit. $A_{\mathrm{H}_{9}}$ and $A_{\mathrm{H}_{8}}$ are the integral areas of the benzyl bromide groups and the methyl protons, respectively.

Ion exchange capacity (IEC). The ion exchange capacity (IEC) of the membranes in the $\mathrm{OH}^{-}$form was measured using the acid-base titration method in triplicate. The membranes were dried in a vacuum oven at $60{ }^{\circ} \mathrm{C}$ for $48 \mathrm{~h}$, accurately weighted, and immersed in $40 \mathrm{~mL}$ of a $0.05 \mathrm{M}$ hydrochloric acid solution. Then the samples were equilibrated for at least $48 \mathrm{~h}$ under an argon atmosphere. The resulting solutions were titrated with a standardized $0.08 \mathrm{M}$ sodium hydroxide solution. The IEC $\left(\mathrm{mmol} \mathrm{g}^{-1}\right)$ was described as

$$
\mathrm{IEC}=\frac{M_{2} V_{2}-M_{1} V_{1}}{W_{\mathrm{d}}},
$$

where $M_{1}(\mathrm{M})$ and $V_{1}(\mathrm{~mL})$ are the concentration and the volume of hydrochloric acid before equilibrium was reached. $M_{2}(\mathrm{M})$ and $V_{2}(\mathrm{~mL})$ refer to the concentration and volume of the standardized sodium hydroxide solution used for titration. $W_{\mathrm{d}}$ is the mass of the dry samples.

Water uptake and swelling ratio. The weight and the thicknesses of dried QPEEK membranes, placed in a vacuum oven at $60{ }^{\circ} \mathrm{C}$ for $48 \mathrm{~h}$, were measured and then recorded as $W_{\text {dry }}$ and $D_{\text {dry }}$, respectively. All membranes were subsequently immersed into deionized water at different temperatures for $24 \mathrm{~h}$, and the weight and the thickness of wet membranes were immediately measured after quickly wiping off the extra water on the surface and recorded as $W_{\text {wet }}$ and $D_{\text {wet }}$, respectively. The water uptake (WU) and the swelling ratio (SR) were characterized using the following equations, respectively:

$$
\text { Water uptake }(100 \%)=\frac{W_{\text {wet }}-W_{\text {dry }}}{W_{\text {dry }}} \times 100 \% \text {, }
$$

$$
\text { Swelling } \operatorname{ratio}(100 \%)=\frac{D_{\text {wet }}-D_{\text {dry }}}{D_{\text {dry }}} \times 100 \% \text {, }
$$

The hydration number $(\lambda)$ represents the average number of water molecules, absorbed by each QA group, and was calculated using the following equation:

$$
\lambda=\frac{\mathrm{WU} \times 10}{\mathrm{IEC} \times 18}
$$

Hydroxide conductivity. Hydroxide conductivity $(\sigma)$ was measured with a Princeton Applied Research 2273 potentiostat/ galvanostat/frequency response analyzer using a four-probe AC impedance method, frequency ranging from $1 \mathrm{~Hz}$ to $1 \mathrm{MHz}$. The thickness of all membranes $(1 \mathrm{~cm} \times 4.5 \mathrm{~cm})$ was measured before measuring $\sigma$. The test cell with the membrane was immersed in deionized water to keep $100 \%$ relative humidity at the tested temperature. The hydroxide conductivity $(\sigma)$ was characterized by the following equation:

$$
\sigma=\frac{L}{R S}
$$

where $L$ is the distance between the electrodes $(\mathrm{cm}), R$ is the membrane resistance and $S$ is the cross-sectional area of membrane $\left(\mathrm{cm}^{2}\right)$.

The slopes in Arrhenius plots of the logarithm of the ion conductivity versus $1000 / T$ can be used to estimate the apparent activation energies $\left(E_{\mathrm{a}}\right)$ using the following equation:

$$
\sigma=A \exp \left(-E_{\mathrm{a}} / R T\right)
$$

where $\sigma, A, E_{\mathrm{a}}, R$ and $T$ represent the hydroxide conductivity, a frequency factor, the apparent activation energy, the gas constant and the temperature, respectively. The apparent activation energy is estimated from the slopes of the $\ln \sigma v s .1000 / T$ curves.

Alkaline stability of AEMs. The membranes in hydroxide $\left(\mathrm{OH}^{-}\right)$counterion form were labeled as 0 day's sample. Then, QPEEK membranes were kept in $1 \mathrm{M} \mathrm{NaOH}$ aqueous solution at $60{ }^{\circ} \mathrm{C}$ for 1 day to 24 days, taken out at each interval, washed with deionized water ten times to remove extra ions and tested for hydroxide conductivity. The alkaline stability of AEMs was estimated using the remaining hydroxide conductivity after immersing them in $1 \mathrm{M} \mathrm{NaOH}$ at $60{ }^{\circ} \mathrm{C}$ for a desired time period. In addition, the mechanical properties and the changes in ${ }^{1} \mathrm{H}$ NMR spectra were also used to evaluate the relative stabilities of QPEEKs in $\mathrm{OH}^{-}$form after immersing them in $1 \mathrm{M}$ $\mathrm{NaOH}$ at $60{ }^{\circ} \mathrm{C}$ for $24 \mathrm{~d}$.

\section{Results and discussion}

\section{Evaluating alkaline stability via degradation of model compounds}

Fig. 1 shows the ${ }^{1} \mathrm{H}$ NMR spectra of model compounds QTMA, QMPY, QMPRD, QMIDZ and QMMPH. For the QMPY model compound, the chemical shifts around 7.58-7.51 ppm $\left(\mathrm{H}_{1,2,3}\right)$, $4.60 \mathrm{ppm}\left(\mathrm{H}_{4}\right)$ and $2.90 \mathrm{ppm}\left(\mathrm{H}_{7}\right)$ were assigned to the protons 


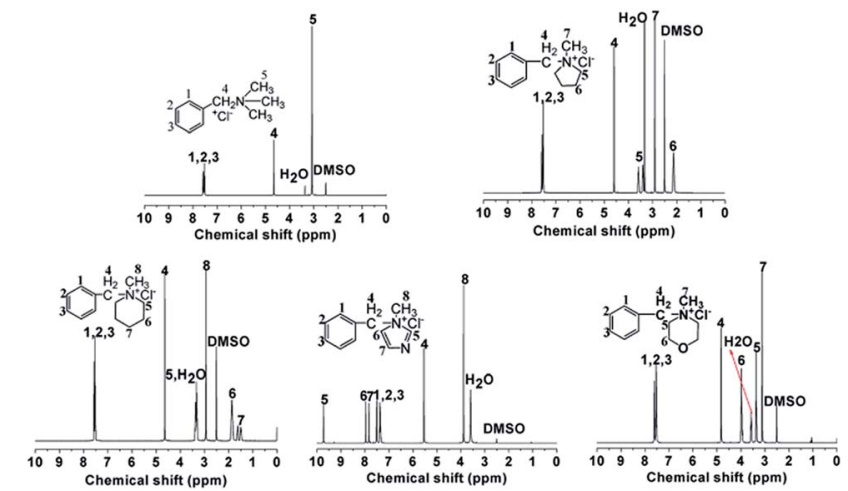

Fig. 1 The ${ }^{1} \mathrm{H}$ NMR spectra of model compounds QTMA, QMPY, QMPRD, QMIDZ and QMMPH.

on the phenyl, benzyl and methyl groups, respectively. Besides, the peaks around $3.50 \mathrm{ppm}\left(\mathrm{H}_{5}\right)$ and $2.2 \mathrm{ppm}\left(\mathrm{H}_{6}\right)$ were assigned to the protons on methylene groups of MPY. Similar characteristic peaks were observed in other ${ }^{1} \mathrm{H}$ NMR spectra of model compounds, which indicated that all the model compounds were synthesized successfully.

To monitor the process of degradation and thoroughly investigate the alkaline stability of hetero-cycloaliphatic QA groups, ${ }^{1} \mathrm{H}$ NMR spectra of model compounds QMPY, QMPRD, QMIDZ and QMMPH alkali aging in $1 \mathrm{M} \mathrm{NaOH} / \mathrm{D}_{2} \mathrm{O}$ at $60{ }^{\circ} \mathrm{C}$ were periodically measured for 18 days, as shown in Fig. 2 . QTMA was also investigated at the same conditions so that its degradation pattern could be used as a reference for all model compounds. The water peak at $4.78 \mathrm{ppm}$ was chosen as the internal reference on account of its integral area being nearly constant in the process. Then we could obtain the remaining fraction of the model compounds at a desired period of up to 18 days by calculating the relative integral area of proton resonances on the phenyl groups, which is presented in Fig. 2(f). During the test, QTMA, QMPY, QMPRD and QMMPH solutions were clear and transparent, but QMIDZ solution turned into a pale yellow emulsion and produced yellow oil droplets after 4 days. In order to continue the alkaline stability test of QMIDZ, the light-yellow supernatant was taken out each day. As shown in Fig. 2(f), these model compounds showed a fast degradation in the first 6 days and then reached a plateau after the 7th day. As shown in Fig. 2(d) and (f), the relative integral area of proton resonances of QMIDZ and QMMPH decreased significantly as the aging time increased.

After 18 days of aging, QMIDZ and QMMPH exhibited degradation of $52.5 \%$ and $64.2 \%$, respectively. However, the degradation degree of QMPY and QMPRD with saturated aliphatic-heterocyclic QA head-groups, calculated from their ${ }^{1} \mathrm{H}$ NMR spectra, was just $24.1 \%$ and $28.9 \%$, respectively; these values were much lower than those of QMIDZ and QMMPH. Importantly, the degradation degree of QMPY and QMPRD was also much lower than that of conventional QTMA (47.3\%), indicating that pyrrolidium and piperidium head-groups were found to have higher stability as compared to benzyltrimethylammonium head-group. These degradations, except for that of QTMA, were mostly due to the ring-opening reaction

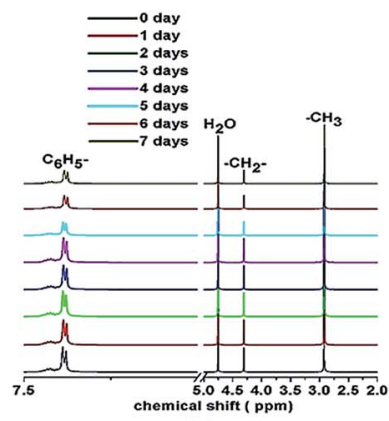

(a)

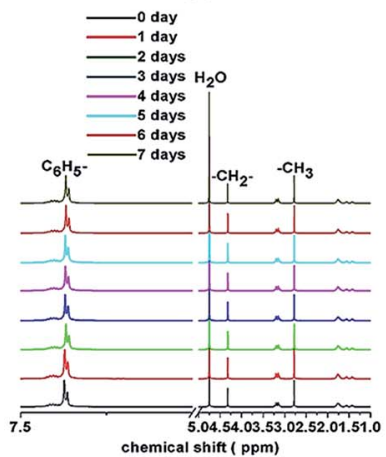

(c)

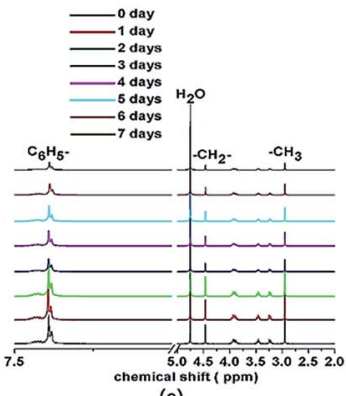

(e)

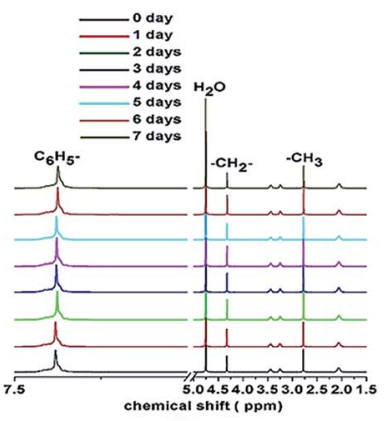

(b)

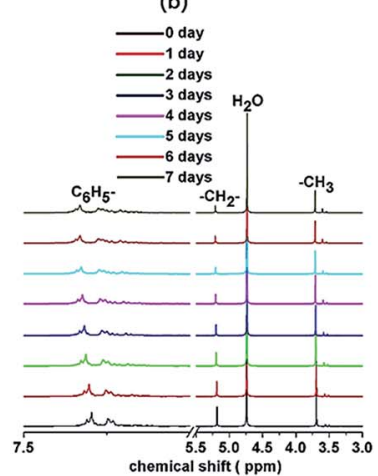

(d)

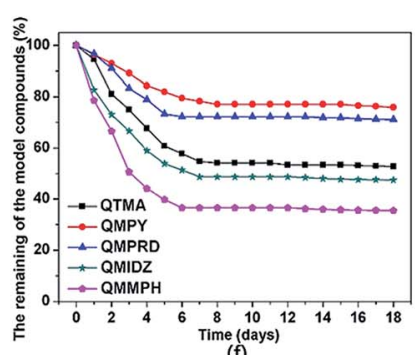

$(f)$
Fig. 2 The ${ }^{1} \mathrm{H}$ NMR spectra of QTMA (a), QMPY (b), QMPRD (c), QMIDZ (d) and QMMPH (e) model compounds aged in $1 \mathrm{M} \mathrm{NaOD} / \mathrm{D}_{2} \mathrm{O}$ at $60{ }^{\circ} \mathrm{C}$, and the remaining fraction of the model compounds in $1 \mathrm{M}$ $\mathrm{NaOD} / \mathrm{D}_{2} \mathrm{O}(\mathrm{f})$.

caused by the $\mathrm{OH}^{-}$nucleophilic attack. From these results, it is clear that the alkaline stability of all model compounds follows the order of QMPY > QMPRD > QTMA > QMIDZ > QMMPH. This conclusion can be used to select the type of QAs for the preparation of QPEEKs and analyze the alkaline stability of the AEM.

\section{Structural characterization of QPEEKs}

The ${ }^{1}$ HNMR spectra of PEEK and BrPEEK are shown in Fig. 3. The chemical shifts at around $4.50 \mathrm{ppm}$ and $2.24 \mathrm{ppm}$ were assigned to the protons of the benzyl bromide groups $\left(-\mathrm{CH}_{2} \mathrm{Br}\right)$ and the methyl protons $\left(-\mathrm{CH}_{3}\right)$, respectively. The conversion ratio of bromomethylation could be controlled by adjusting the molar proportions of NBS and PEEK. The amounts of $-\mathrm{CHBr}_{2}$, $-\mathrm{CH}_{2} \mathrm{Br}$ and $-\mathrm{CH}_{3}$ after bromomethylation were quantitatively determined by calculating their integral areas and the results are listed in Table 1. The amount of $-\mathrm{CHBr}_{2}$ per repeat unit increased from 0.04 to 0.48 , while the amount of $-\mathrm{CH}_{3}$ 


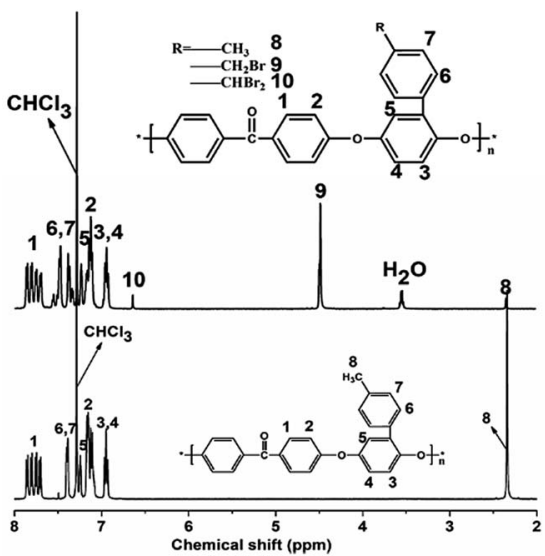

Fig. 3 The ${ }^{1} \mathrm{H}$ NMR spectra of PEEK and BrPEEK-1.2.

Table 1 The amounts of $-\mathrm{CHBr}_{2},-\mathrm{CH}_{2} \mathrm{Br}$ and $-\mathrm{CH}_{3}$ per repeat unit after bromomethylation

\begin{tabular}{llll}
\hline NBS/PEEK & $-\mathrm{CHBr}_{2}$ & $-\mathrm{CH}_{2} \mathrm{Br}$ & $-\mathrm{CH}_{3}$ \\
\hline 2.0 & 0.48 & 0.46 & 0 \\
1.5 & 0.32 & 0.62 & 0 \\
1.4 & 0.20 & 0.68 & 0 \\
1.3 & 0.16 & 0.74 & 0 \\
1.2 & 0.12 & 0.78 & 0.04 \\
1.1 & 0.07 & 0.76 & 0.12 \\
1.0 & 0.04 & 0.74 & 0.23
\end{tabular}

decreased from 0.23 to 0 , as NBS/PEEK was adjusted from 1.0 to 2.0. Meanwhile, the amount of the target group $-\mathrm{CH}_{2} \mathrm{Br}$ per repeat unit (DBr) increased slightly from 0.74 to 0.78 and then decreased to 0.46 when NBS/PEEK increased from 1.0 to 2.0. In the following procedure, the intermediate product BrPEEK with the highest $\mathrm{DBr}$ of 0.78 was chosen to be the precursor for tethering hetero-cycloaliphatic QA groups.

The ${ }^{1} \mathrm{H}$ NMR spectra of QPEEKs are shown in Fig. 4. For QPEEK-MPY, the chemical shift around $4.70 \mathrm{ppm}\left(\mathrm{H}_{9}\right)$ was assigned the protons of $-\mathrm{CH}_{2}-\mathrm{N}$ groups; meanwhile, $2.80 \mathrm{ppm}$ $\left(\mathrm{H}_{11}\right)$ and $2.10 \mathrm{ppm}\left(\mathrm{H}_{12}\right)$ corresponded to the protons of $-\mathrm{CH}_{2}-$ groups in MPY ring. Similar peaks were found in the other spectra of QPEEK-TMA, QPEEK-MPRD, QPEEK-MMPH and

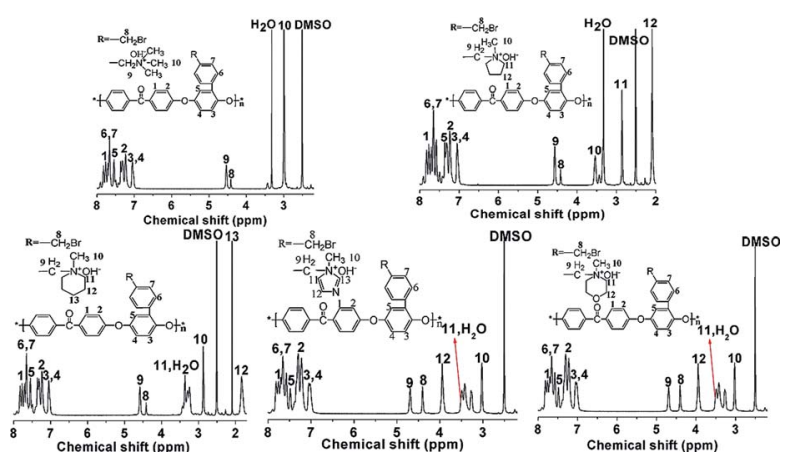

Fig. 4 The ${ }^{1} \mathrm{H}$ NMR spectra of QPEEK-TMA, QPEEK-MPY, QPEEKMPRD, QPEEK-MIDZ and QPEEK-MMPH.

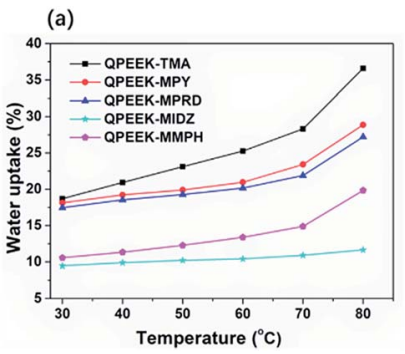

(b)

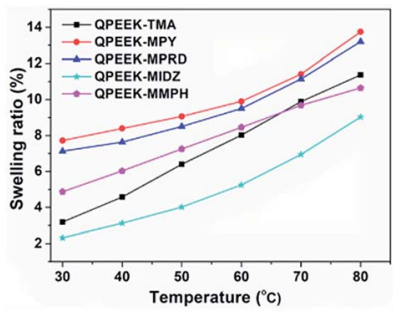

Fig. 5 Water uptake and swelling ratio of QPEEKs.

QPEEK-MIDZ (Fig. 5). These QPEEKs were synthesized successfully and all conversion ratios from BrPEEK were between $80-85 \%$, obtained by calculating the integration ratio of quaternized ammonium benzyl groups $\left(\mathrm{H}_{9}\right)$ to brominated benzyl groups $\left(\mathrm{H}_{8}\right)$.

As presented in Table 2, the theoretical IEC, calculated using the ${ }^{1} \mathrm{H}$ NMR spectra, was in the range of 1.10 to $1.74 \mathrm{mmol} \mathrm{g}^{-1}$. The experimental values obtained by the titration method varied from 0.99 to $1.63 \mathrm{mmol} \mathrm{g}^{-1}$. The experimental IEC of these QPEEK membranes was line with the theoretical value, implying the successful Menschutkin reaction. QPEEK-TMA, QPEEK-MPY and QPEEK-MPRD exhibited similar IEC values of $1.63 \mathrm{mmol} \mathrm{g}^{-1}, 1.49 \mathrm{mmol} \mathrm{g}^{-1}$ and $1.52 \mathrm{mmol} \mathrm{g}^{-1}$, respectively. QPEEK-MIDZ and QPEEK-MMPH had relatively lower IECs than those of the first three membranes.

\section{Water uptake and swelling ratio}

Water uptake plays an important role in determining performance of ion-exchange membrane materials. According to the vehicle mechanism, ions can not penetrate membranes unless they are hydrated by water. However, excessive water uptake results in a high swelling ratio, which damages the dimensional stability and the mechanical properties of AEMs. Therefore, it is very important to control the water uptake and the swelling ratio in a reasonable range. Water uptake and the swelling ratio of QPEEKs in the $\mathrm{OH}^{-}$form as a function of temperature, ranging from $30^{\circ} \mathrm{C}$ to $80^{\circ} \mathrm{C}$, are shown in Fig. 5 . Both the water uptake and the swelling ratio of these membranes increased with increasing temperature. The QPEEKs with heterocycloaliphatic QA head-groups showed much lower water uptake than QPEEK-TMA $\left(18.7 \%\right.$ at $30{ }^{\circ} \mathrm{C}$ and $36.6 \%$ at $\left.80{ }^{\circ} \mathrm{C}\right)$. For example, QPEEK-MPY and QPEEK-MPRD exhibited similar water uptake of $18.1 \%$ and $17.5 \%$ at $30{ }^{\circ} \mathrm{C}$ as well as $28.9 \%$ and $27.2 \%$ at $80{ }^{\circ} \mathrm{C}$, respectively. Furthermore, QPEEK-MPY and QPEEK-MPRD exhibited similar swelling ratios. Different from water uptake, their swelling ratios were higher than that of QPEEK-TMA $\left(3.2 \%\right.$ at $30{ }^{\circ} \mathrm{C}$ and $11.4 \%$ at $\left.80 \%\right)$ with similar IECs. Besides, the corresponding $\lambda$ of QPEEK-TMA, QPEEK-MPY and QPEEK-MPRD was in the range of 6.37 to 6.76, which was higher than the values for QPEEK-MIDZ and QPEEK-MMPH. On the whole, the changes in water uptake and $\lambda$ were in line with the change in IEC. 
Table 2 Ion exchange capacity, water uptake at $80^{\circ} \mathrm{C}$, and hydroxide conductivity at $80^{\circ} \mathrm{C}$ of QPEEKs

\begin{tabular}{|c|c|c|c|c|c|}
\hline Sample & $\operatorname{IEC}^{a}\left(\mathrm{mmol} \mathrm{g}^{-1}\right)$ & $\operatorname{IEC}^{b}\left(\mathrm{mmol} \mathrm{g}^{-1}\right)$ & Water uptake (\%) & $\sigma\left(\mathrm{mS} \mathrm{cm}^{-1}\right)$ & $\lambda\left(\mathrm{OH}^{-}\right)$ \\
\hline QPEEK-TMA & 1.74 & 1.63 & 36.6 & 40.5 & 6.37 \\
\hline QPEEK-MPY & 1.68 & 1.49 & 28.9 & 39.9 & 6.76 \\
\hline QPEEK-MIDZ & 1.14 & 1.03 & 11.6 & 37.4 & 5.11 \\
\hline QPEEK-MMPH & 1.10 & 0.99 & 19.8 & 33.1 & 5.93 \\
\hline
\end{tabular}

${ }^{a}$ Calculated from ${ }^{1} \mathrm{H}$ NMR spectra. ${ }^{b}$ Estimated by titration. $\lambda$ average number of $\mathrm{H}_{2} \mathrm{O}$ per quaternary ammonium group at $30{ }^{\circ} \mathrm{C}$. Water uptake and $\sigma$ were measured at $80{ }^{\circ} \mathrm{C}$.

\section{Thermal stability}

The TGA curves of QPEEKs are shown in Fig. 6. All these TGA curves exhibited two thermal decomposition stages with the temperature variation from $100{ }^{\circ} \mathrm{C}$ to $800{ }^{\circ} \mathrm{C}$ under nitrogen atmosphere. The temperature of the first weight loss, assigned to the decomposition of QAs on side chains, was approximately $200{ }^{\circ} \mathrm{C}$ and no further decomposition was observed. The temperature of the second weight loss, assigned to the decomposition of the main chains of QPEEK, was approximately $490{ }^{\circ} \mathrm{C}$. Moreover, QPEEK-TMA, QPEEK-MPY and QPEEK-MIDZ exhibited similar $T_{\mathrm{d} 5 \%}$ of $279.1{ }^{\circ} \mathrm{C}, 272.8{ }^{\circ} \mathrm{C}$ and $273.6{ }^{\circ} \mathrm{C}$, respectively. QPEEK-MPRD exhibited a relatively higher $T_{\mathrm{d} 5 \%}$ of $286.0{ }^{\circ} \mathrm{C}$ and QPEEK-MMPH displayed the highest $T_{\mathrm{d} 5 \%}$ of $299.3{ }^{\circ} \mathrm{C}$. The $T_{\mathrm{d} 5 \%}$ of all these QPEEKs was higher than $270{ }^{\circ} \mathrm{C}$. Besides, the residual weight percentage of all these QPEEKs at $800{ }^{\circ} \mathrm{C}$ was in the range of $59.1 \sim 61.5 \%$. Therefore, all membranes possessed sufficient thermal stability for potential application in construction of fuel cells. ${ }^{28}$

\section{Mechanical properties}

The mechanical properties of QPEEKs, measured in the dry state, are listed in Table 3. QPEEKs exhibited tensile strength from 43.8 $\mathrm{MPa}$ to $68.8 \mathrm{MPa}$, Young's modulus from 590.2 $\mathrm{MPa}$ to 911.1 MPa and the elongation at break from $10.2 \%$ to $70.0 \%$. QPEEK-MIDZ had a maximum tensile strength of $68.8 \mathrm{MPa}$ and a maximum Young's modulus of 911.1 MPa, while QPEEK-MMPH had a maximum elongation at break of $70.0 \%$. According to the tensile strength of QPEEKs presented in Table 2, the mechanical strength of QPEEKs follows the order: QPEEK-MIDZ > QPEEK-

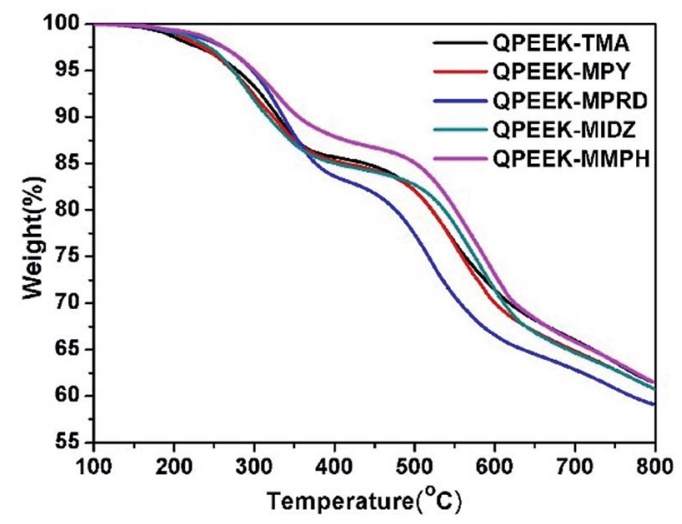

Fig. 6 TGA curves of QPEEKs.
Table 3 Mechanical Properties of QPEEKs

\begin{tabular}{llll}
\hline Sample & $\begin{array}{l}\text { Tensile } \\
\text { strength (MPa) }\end{array}$ & $\begin{array}{l}\text { Elongation } \\
\text { at break (\%) }\end{array}$ & $\begin{array}{l}\text { Young's } \\
\text { modulus (MPa) }\end{array}$ \\
\hline QPEEK-TMA & $43.8 \pm 2.2$ & $16.5 \pm 2.5$ & $590.2 \pm 127.7$ \\
QPEEK-MPY & $46.2 \pm 1.0$ & $18.0 \pm 2.1$ & $771.6 \pm 63.6$ \\
QPEEK-MPRD & $46.0 \pm 0.7$ & $10.2 \pm 1.2$ & $820.9 \pm 62.0$ \\
QPEEK-MIDZ & $68.8 \pm 4.8$ & $27.9 \pm 3.7$ & $911.1 \pm 131.8$ \\
QPEEK-MMPH & $60.0 \pm 6.7$ & $70.0 \pm 2.9$ & $801.5 \pm 75.5$
\end{tabular}

MMPH > QPEEK-QMPY $\approx$ QPEEK-MPRD > QPEEK-TMA. The AEMs with hetero-cycloaliphatic QA head-groups had higher tensile strength than QPEEK-TMA, indicating that they were strong enough to be applied in fuel cell construction.

\section{Hydroxide conductivity}

Hydroxide conductivity is the core parameter used to determine the performance of AEMs. The hydroxide conductivities of QPEEKs as the function of temperature are shown in Fig. 7(a). The hydroxide conductivities of all these membranes increased with increasing temperature. The hydroxide conductivities of QPEEK-MPY (39.9 $\mathrm{mS} \mathrm{cm}^{-1}, 80{ }^{\circ} \mathrm{C}$ ) and QPEEK-MPRD (38.8 $\mathrm{mS} \mathrm{cm}{ }^{-1}, 80{ }^{\circ} \mathrm{C}$ ) were slightly lower than that of QPEEK-TMA (40.5 $\mathrm{mS} \mathrm{cm}^{-1}, 80^{\circ} \mathrm{C}$ ), but higher than those of QPEEK-MIDZ $\left(37.4 \mathrm{mS} \mathrm{cm}^{-1}, 80{ }^{\circ} \mathrm{C}\right)$ and QPEEK-MMPH (33.08 $\mathrm{mS} \mathrm{cm}^{-1}, 80$ $\left.{ }^{\circ} \mathrm{C}\right)$. Using the Arrhenius plots of hydroxide conductivity displayed in Fig. 7(b), the apparent activation energies of QPEEKs were calculated from the slopes of the lines: $13.8 \mathrm{~kJ} \mathrm{~mol}^{-1}$ for QPEEK-TMA, $14.8 \mathrm{~kJ} \mathrm{~mol}^{-1}$ for QPEEK-MPY, $15.2 \mathrm{~kJ} \mathrm{~mol}^{-1}$ for QPEEK-MPRD, $16.2 \mathrm{~kJ} \mathrm{~mol}^{-1}$ for QPEEK-MIDZ and $19.0 \mathrm{~kJ} \mathrm{~mol}^{-1}$ for QPEEK-MMPH, respectively. The lower apparent activation energies of QPEEK-MPY and QPEEK-MPRD indicated that their hydroxide conductivity could be enhanced,

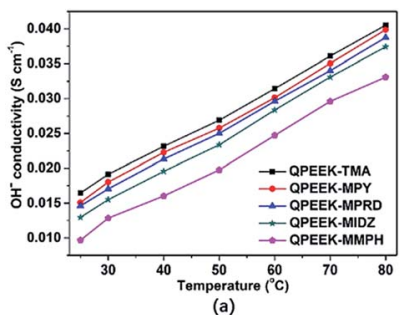

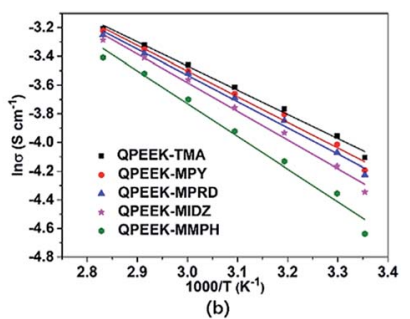

(b)
Fig. 7 Hydroxide conductivity of QPEEKs (a) and Arrhenius plots of hydroxide conductivity of QPEEKs (b). 


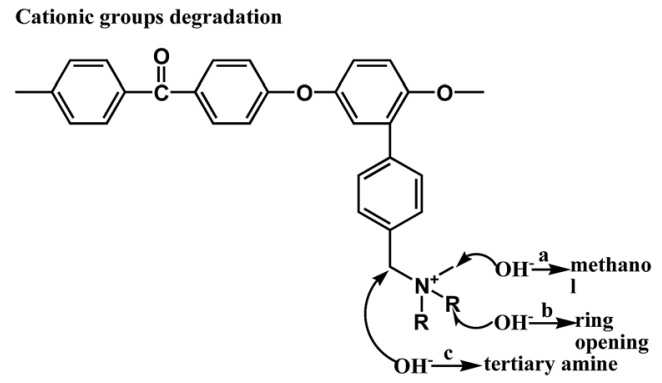

Backbone degradation

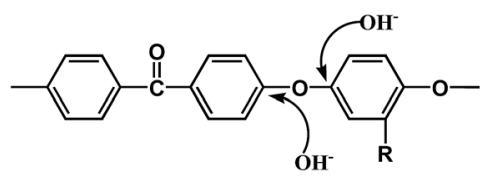

Fig. 8 Possible $\mathrm{OH}^{-}$promoted degradation pathways in QPEEKs membranes.

presumably, due to better dissociation, thus, facilitating the mobility of $\mathrm{OH}^{-}$anions. ${ }^{29,30}$

\section{Evaluating the alkaline stability of AEMs using hydroxide conductivity}

Since AEMs must be stable in a strongly alkaline environment, alkaline stability is one of the important parameters of AEMs for their practical application in AEMFCs. As reported earlier regarding methyl-containing head groups, there are three possible pathways of cationic groups' degradation, presented in Fig. 8. Pathway a is the $\mathrm{S}_{\mathrm{N}} 2$ substitution of the methyl group, resulting in loss of methanol and yielding a polymer containing a benzyl-linked secondary amine. ${ }^{31}$ Pathway b is a nucleophilic attack or Hofmann elimination reaction that leads to heterocyclic ring opening. ${ }^{32}$ Pathway $\mathrm{c}$ is a nucleophilic attack at the benzylic $\Phi-\mathrm{CH}_{2}-\mathrm{N}$ which is especially sensitive. ${ }^{33}$ Besides, there is backbone degradation due to cleavage of aryl ether $\left(\mathrm{C}_{\mathrm{sp}^{2}}-\mathrm{O}\right)$ bonds, as shown in Fig. $8 .^{25}$

As shown in Table 4, the mechanical properties of QPEEKs, such as strength, elongation and modulus loss, declined after the $\mathrm{OH}^{-}$treatment for $24 \mathrm{~d}$. This occured mainly because that aryl ether-containing polymers underwent polymer backbone degradation via cleavage of $\mathrm{C}-\mathrm{O}$ bonds under alkaline conditions, ${ }^{34,35}$ as shown in Fig. 8.

The change in the hydroxide conductivity as a function of time was used to evaluate the relative stability of QPEEKs in the $\mathrm{OH}^{-}$form by immersing them in $1 \mathrm{M} \mathrm{NaOH}$ at $60{ }^{\circ} \mathrm{C}$. The

Table 4 Mechanical properties of QPEEKs membranes after treatment with $\mathrm{OH}^{-}$for $24 \mathrm{~d}$

\begin{tabular}{llll}
\hline Sample & $\begin{array}{l}\text { Tensile } \\
\text { strength }(\mathrm{MPa})\end{array}$ & $\begin{array}{l}\text { Elongation } \\
\text { at break }(\%)\end{array}$ & \multicolumn{1}{l}{$\begin{array}{l}\text { Young's } \\
\text { modulus (MPa) }\end{array}$} \\
\hline QPEEK-TMA & $34.5 \pm 5.2$ & $5.3 \pm 0.5$ & $472.3 \pm 77.0$ \\
QPEEK-MPY & $30.7 \pm 8.3$ & $5.7 \pm 0.8$ & $421.7 \pm 38.1$ \\
QPEEK-MPRD & $15.5 \pm 2.7$ & $1.8 \pm 0.3$ & $291.2 \pm 42.0$ \\
QPEEK-MIDZ & $61.9 \pm 2.4$ & $17.0 \pm 5.4$ & $492.6 \pm 58.8$ \\
QPEEK-MMPH & $53.3 \pm 2.4$ & $23.6 \pm 2.9$ & $528.3 \pm 31.3$
\end{tabular}

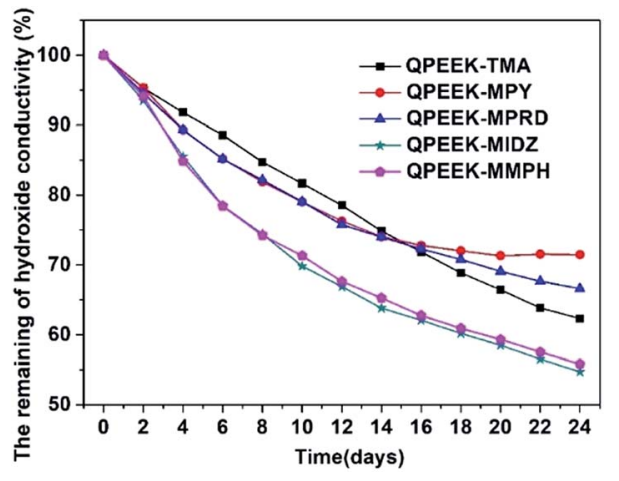

Fig. 9 The remaining hydroxide conductivity of QPEEKs membranes in the $\mathrm{OH}^{-}$form after soaking them in $1 \mathrm{M} \mathrm{NaOH}$.

remaining hydroxide conductivity at $80^{\circ} \mathrm{C}$ of the QPEEKs in the $\mathrm{OH}^{-}$form is shown Fig. 9. The hydroxide conductivities of all these QPEEKs decreased as the immersion time increased. After immersing the AEMs in $1 \mathrm{M} \mathrm{NaOH}$ at $60^{\circ} \mathrm{C}$ for 24 days, QPEEKMIDZ and QPEEK-MMPH showed a significant loss in hydroxide conductivity $(>40 \%)$, caused by lower alkaline stability of benzylmethylimidazolium and benzylmethylmorpholinium at high temperature. QPEEK-TMA displayed a slightly lower loss than QPEEK-MPY and QPEEK-MPRD in the first 15 days. But after 24 days, QPEEK-MPY and QPEEK-MPRD exhibited the hydroxide conductivity losses of $28.5 \%$ and $33.4 \%$, respectively, which were lower than that of QPEEK-TMA (37.7\%). For QPEEK-TMA, QPEEK-MPY and QPEEK-MPRD, a new signal appeared around $5.85 \mathrm{ppm}$ in ${ }^{1} \mathrm{H}$ NMR spectrum, assigned to the proton of the $\mathrm{OH}$ group of phenol, and the peak shapes showed some differences between 7 ppm and $8 \mathrm{ppm}$ after storage in $1 \mathrm{M} \mathrm{NaOH}$ at $60{ }^{\circ} \mathrm{C}$ for 24 days (Fig S1, S2 and $\mathrm{S} 3 \dagger$ ), possibly induced by QPEEKs polymer backbone scission of those membranes. The integrated area ratio of $\mathrm{Ar}-\mathrm{CH}_{2}-$ $\mathrm{N}^{+}\left(A_{1}\right)$ and $-\mathrm{CH}_{2}-\mathrm{Br}$ or $-\mathrm{CH}_{2}-\mathrm{OH}\left(A_{0}\right)$ is also recorded in Fig $\mathrm{S} 1$, S2 and S3. $\dagger$ The changes of $A_{1}: A_{0}$ before and after the $\mathrm{OH}^{-}$ treatment were due to the degradation of cationic groups, possibly via pathways a, b and c, shown in Fig. 8. This would cause the functional group loss and, then, conductivity loss. The degradation of polymer backbone could cause cationic group loss by dissolving low $M_{\mathrm{w}}$ and highly functionalized polymer fragment, which resulted in conductivity loss. It should be noted that the alkaline stability of QPEEKs membranes was not completely consistent with that of model compounds. This occured mainly because the alkaline stability of QPEEKs was comprehensively affected by many factors: QPEEKs structure, different experimental conditions, different water uptake, etc. The anion exchange membrane exhibited a relatively high local $\mathrm{pH}$ in alkaline solution and a low water uptake, which led to more degradation. It is why the alkaline stability of QPEEKMMPH and QPEEK-MIDZ was not consistent with that of QMIDZ and QMMPH.

\section{Conclusions}

Several model compounds with aliphatic-heterocyclic QA headgroups were synthesized and their alkaline stability was 
characterized by ${ }^{1} \mathrm{H}$ NMR. Our results indicated that the alkaline stability of these model compounds followed the order of QMPY > QMPRD > QTMA > QMIDZ > QMMPH. Then, a series of AEMs with aliphatic-heterocyclic QA head-groups on the side chains were prepared and compared with QPEEK-TMA. These QPEEKs exhibited sufficient thermal, dimensional and mechanical stability. QPEEK-MPY, QPEEK-MPRD and QPEEKTMA exhibited similar $\mathrm{OH}^{-}$conductivities of $39.9 \mathrm{mS} \mathrm{cm}^{-1}$, $38.8 \mathrm{mS} \mathrm{cm}^{-1}$ and $40.5 \mathrm{mS} \mathrm{cm}^{-1}$ at $80{ }^{\circ} \mathrm{C}$ and $100 \%$ relative humidity. Furthermore, after a 24 days' test, QPEEK-MPY and QPEEK-MPRD possessed better alkaline stability after their immersion in $1 \mathrm{M} \mathrm{NaOH}$ solution at $60{ }^{\circ} \mathrm{C}$. They exhibited conductivity loss of $28.5 \%$ and $33.4 \%$, respectively, which was lower than that of QPEEK-TMA (37.7\%). All parameters indicate that QPEEK-MPY and QPEEK-MPRD can be potential components of AEMFCs, especially QPEEK-MPY, which exhibited the best overall performance.

\section{Conflicts of interest}

There are no conflicts to declare.

\section{Acknowledgements}

We acknowledge the financial support from the Natural Science Foundation of China (No. 21474036).

\section{Notes and references}

1 A. B. Rao and E. S. Rubin, Environ. Sci. Technol., 2002, 36, 4467.

2 N. Li and M. D. Guiver, Macromolecules, 2014, 47, 2175-2198.

3 J. R. Varcoe, P. Atanassov, D. R. Dekel, A. M. Herring, M. A. Hickner, P. A. Kohl, A. R. Kucernak, W. E. Mustain, K. Nijmeijer and K. Scott, Energy Environ. Sci., 2014, 7, 3135-3191.

4 G. J. K. Acres, J. Power Sources, 2001, 100, 60-66.

5 Y. J. Wang, J. Qiao, R. Baker and J. Zhang, Chem. Soc. Rev., 2013, 42, 5768-5787.

6 C. Chen, J. Pan, J. Han, Y. Wang, L. Zhu, M. A. Hickner and L. Zhuang, J. Mater. Chem. A, 2016, 4, 4071-4081.

7 C. Chen, Y. L. S. Tse, G. E. Lindberg, C. Knight and G. A. Voth, J. Am. Chem. Soc., 2016, 138, 991.

8 S. Chempath, B. R. Einsla, L. R. Pratt, C. S. Macomber and J. M. Boncella, J. Phys. Chem. C, 2017, 112, 3179-3182.

9 J. R. Varcoe, R. C. T. Slade and T. N. Danks, J. Mater. Chem., 2003, 13, 712-721.

10 C. E. Diesendruck and D. R. Dekel, Curr. Opin. Electrochem., 2018, 9, 173-178.

11 C. H. Park, S. Y. Lee, D. S. Hwang, D. W. Shin, D. H. Cho, K. H. Lee, T. W. Kim, T. W. Kim, M. Lee and D. S. Kim, Nature, 2016, 532, 480.
12 J. Pan, C. Chen, L. Zhuang and J. Lu, Acc. Chem. Res., 2012, 45, 473.

13 F. Bu, C. Zhao, B. Wang, N. Zhang, H. Lu, Z. Cai, Y. Zhang and H. Na, RSC Adv., 2015, 5, 57067-57075.

14 H. S. Dang and P. Jannasch, J. Mater. Chem. A, 2016, 4, 11924-11938.

15 M. G. Marino and K. D. Kreuer, Chemsuschem, 2015, 8, 513523.

16 K. M. Meek, J. R. Nykaza and Y. A. Elabd, Macromolecules, 2016, 49, 3382-3394.

17 F. Gu, H. Dong, Y. Li, Z. Sun and Y. Feng, Macromolecules, 2014, 47, 6740-6747.

18 C. Morandi, R. Peach, H. Krieg and J. Kerres, J. Mater. Chem. A, 2014, 3, 1110-1120.

19 J. Ponce-gonzález, D. K. Whelligan, L. Wang, R. Bancesoualhi, Y. Wang, Y. Peng, H. Peng, D. C. Apperley, H. N. Sarode and T. P. Pandey, Energy Environ. Sci., 2016, 9, 3724-3735.

20 J. Wang, S. Li and S. Zhang, Macromolecules, 2010, 43, 38903896.

21 J. Wang, C. Zhao, H. Lin, G. Zhang, Y. Zhang, J. Ni, W. Ma and H. Na, J. Power Sources, 2011, 196, 5432-5437.

22 J. Pang, S. Feng, Y. Yu, H. Zhang and Z. Jiang, Polym. Chem., 2014, 5, 1477-1486.

23 B. Qiu, B. Lin, L. Qiu and F. Yan, J. Mater. Chem., 2011, 22, 1040-1045.

24 B. Qiu, B. Lin, Z. Si, L. Qiu, F. Chu, J. Zhao and Y. Feng, J. Power Sources, 2012, 217, 329-335.

25 L. Liu, J. Ahlfield, A. Tricker, D. Chu and P. Kohl, J. Mater. Chem. A, 2016, 4, 16233-16244.

26 B. Wang, W. Sun, F. Bu, X. Li, N. Hui and C. Zhao, Int. J. Hydrogen Energy, 2016, 41, 3102-3112.

27 X. Shuai, Z. Gang, Z. Yang, C. Zhao, W. Ma, H. Sun, Z. Na, L. Zhang, J. Hao and N. Hui, J. Power Sources, 2012, 209, 228-235.

28 J. Wang, X. Wang, D. Zu, H. Yang, L. Yan, S. Yang, H. Wei and Y. Ding, J. Membr. Sci., 2017, 545, 116-125.

29 M. Irfan, E. Bakangura, N. U. Afsar, M. M. Hossain, J. Ran and T. Xu, J. Power Sources, 2017, 355, 171-180.

30 A. Le Mong and D. Kim, Electrochim. Acta, 2018, 290, 544555.

31 L. Hai, K. Kim and B. S. Pivovar, J. Phys. Chem. C, 2012, 116, 9419-9426.

32 S. A. Nunez, C. Capparelli and M. A. Hickner, Chem. Mater., 2016, 28, 2589-2598.

33 A. D. Mohanty and C. Bae, J. Mater. Chem. A, 2014, 2, 1731417320.

34 A. Christopher G and R. Vijay, Proc. Natl. Acad. Sci. U. S. A., 2013, 110, 2490-2495.

35 S. Zhe, P. Ji, J. Guo and Y. Feng, Adv. Sci., 2018, 5, 1800065. 